NISTIR 7260

\title{
Analysis of CCRL Portland Cement Proficiency Samples Number 151 and Number 152 Using the Virtual Cement and Concrete Testing Laboratory
}

Jeffrey W. Bullard and Paul E. Stutzman

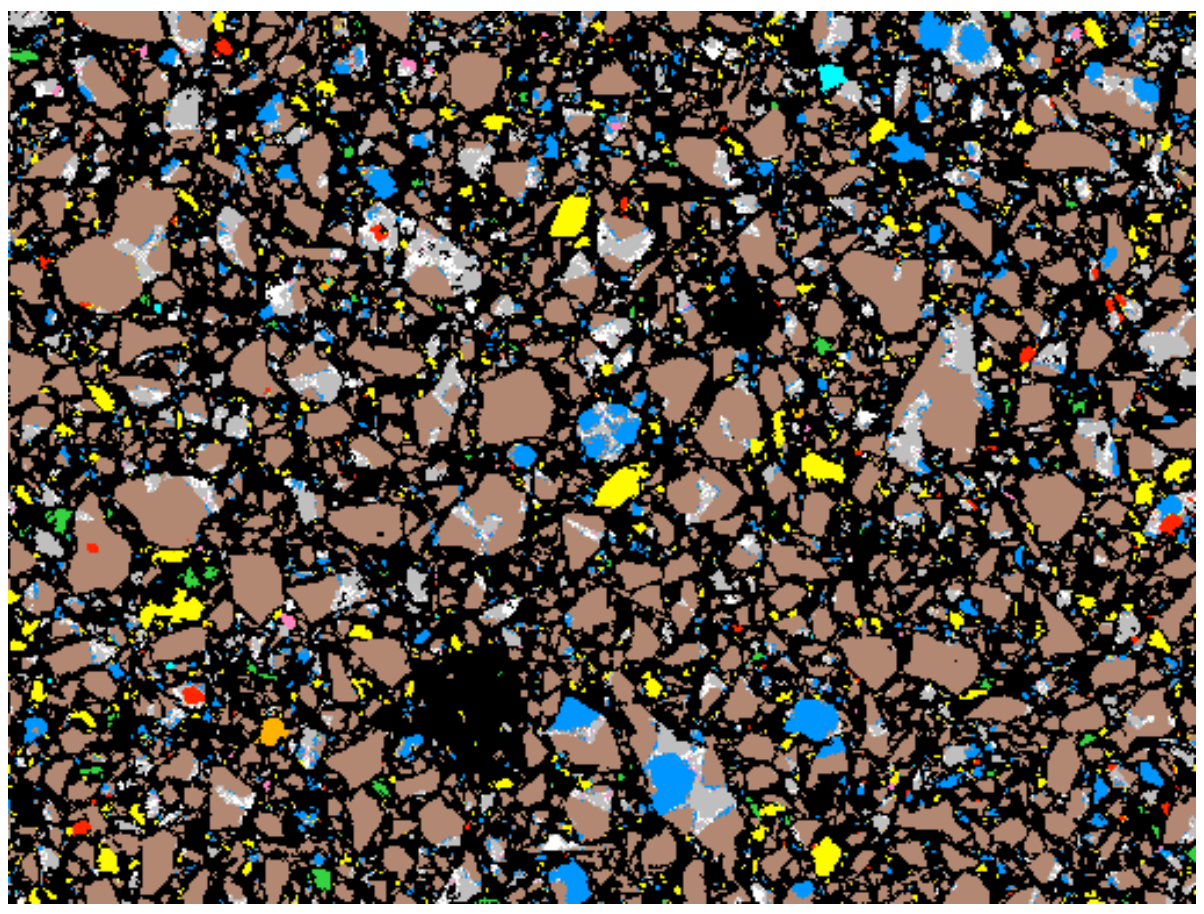


NISTIR 7260

\section{Analysis of CCRL Portland Cement Proficiency Samples Number 151 and Number 152 Using the Virtual Cement and Concrete Testing Laboratory}

Jeffrey W. Bullard and Paul E. Stutzman

Building and Fire Research Laboratory

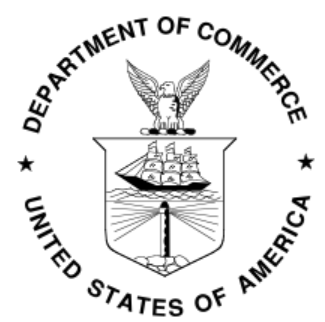

U.S. DEPARTMENT OF COMMERCE

Donald L. Evans, Secretary

TECHNOLOGY ADMINISTRATION

Phillip J. Bond, Under Secretary of Commerce for Technology 


\begin{abstract}
This report provides experimental and computer modeling results for Portland Cement Proficiency Samples 151 and 152 issued by the Cement and Concrete Reference Laboratory (CCRL) at NIST in January of 2004. The purposes of this report are to characterize these cements via scanning electron microscopy (SEM) analysis and to document the ability of the Virtual Cement and Concrete Testing Laboratory (VCCTL) software to predict the hydration kinetics, heat of hydration, and mortar strength development of Portland cements evaluated in the CCRL proficiency sample program. The general procedure to evaluate a new cement is as follows: 1) two-dimensional SEM backscattered electron and $\mathrm{X}$-ray microanalysis images of the cement of interest are obtained, along with a measured particle size distribution (PSD); 2) based on analysis of these images and the measured PSD, three-dimensional cement paste microstructures of various water-to-cement ratios are created and hydrated using VCCTL, and 3 ) the model predictions for degree of hydration under saturated conditions, heat of hydration (ASTM C186), setting time (ASTM C191), and strength development of mortar cubes (ASTM C109) are compared to experimental measurements either performed at NIST or at the participating CCRL proficiency sample evaluation laboratories. For cement 152, generally good agreement is observed between the model predictions and the experimental data. For cement 151, discrepancies between the model predictions and the experimental data are much larger, and possible reasons for these discrepancies are considered.
\end{abstract}

Keywords: Building technology, computer modeling, Virtual Cement and Concrete Testing Laboratory, cement, heat of hydration, hydration kinetics, particle size distribution, SEM imaging, strength development. 


\section{Contents}

Abstract $\quad$ i

List of Figures

List of Tables $\quad$ v

1 Introduction 1

2 Experimental Procedure 1

2.1 Particle Size Distribution . . . . . . . . . . . . . . . . 2

2.2 Microstructure Imaging and Segmentation . . . . . . . . . . . . . . 2

2.3 Stereological Analysis . . . . . . . . . . . . . . . . 4

2.4 Estimating Degree of Hydration . . . . . . . . . . . . . . . . . . . . . . . . . . . . 10

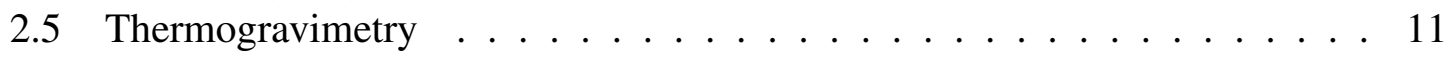

3 Results $\quad 11$

3.1 Hydration Kinetics . . . . . . . . . . . . . . . . . 11

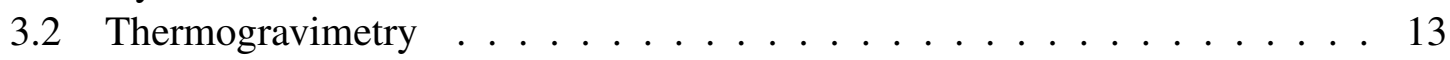

3.3 Heat of Hydration . . . . . . . . . . . . . . . . . 15

3.4 Setting Time . . . . . . . . . . . . . . . . . . . 16

3.5 Mortar Strength Development . . . . . . . . . . . . . . 17

4 Summary 19

$\begin{array}{ll}\text { Acknowledgments } & 19\end{array}$ 


\section{List of Figures}

1 Particle size distributions, plotted as probability density functions, measured for CCRL cements 151 and 152 using laser diffraction from a dilute suspension of particles in anhydrous isopropyl alcohol. . . . . . . . . . .

2 Composite RGB images of cement 151 (left) and cement 152 (right). The degree of red is proportional to the $\mathrm{Ca} \mathrm{X}$-ray signal intensity, green to that for $\mathrm{Si}$, and blue to that for $\mathrm{Al}$. Therefore, shades of yellow correspond to (red/green or $\mathrm{Ca} / \mathrm{Si}$ ) calcium silicate phases and shades of purple correspond to (red/blue or $\mathrm{Ca} / \mathrm{Al})$ calcium aluminate phases. Black regions are epoxy-filled pore space. The image field dimensions are $256 \mu \mathrm{m} \times 200 \mu \mathrm{m}$. $\quad 4$

3 Decision tree for pixel-by-pixel segmentation of a cement image into its mineral components. Conventional cement chemistry notation is used: $\mathrm{C}_{3} \mathrm{~S}$ denotes tricalcium silicate, $\mathrm{C}_{2} \mathrm{~S}$ denotes dicalcium silicate, $\mathrm{C}_{3} \mathrm{~A}$ denotes tricalcium aluminate, and $\mathrm{C}_{4} \mathrm{AF}$ denotes tetracalcium aluminoferrite. Adapted from [1]. . . . . . . . . . . . . . . . . . . . . . . . . Final processed images of cement 151 (top) and cement 152 (bottom). The color coding of each mineral phase is keyed to the accompanying legend. The image field dimensions are $256 \mu \mathrm{m} \times 200 \mu \mathrm{m} . \ldots \ldots . . \ldots . . .99$

5 Computer model (lines) and experimental results (points) for degree of hydration of cement 151 with w/c $=0.35$ (left) and w/c $=0.45$ (right). Circles indicate mean values measured for specimens cured at $23{ }^{\circ} \mathrm{C}$ and squares indicate mean values measured for specimens cured at $60^{\circ} \mathrm{C}$. Filled symbols indicate measurements made with the normal $105^{\circ} \mathrm{C}$ oven, and open symbols indicate measurements made with the dry $105^{\circ} \mathrm{C}$ oven. Error bars on experimental data represent the range of two measurements made on two samples. The dashed curve in each plot is the model prediction for curing at $60{ }^{\circ} \mathrm{C}$ when an effective activation energy of $56.3 \mathrm{~kJ} /$ mole is used. 12 Computer model (lines) and experimental results (points) for degree of hydration of cement 152 with $\mathrm{w} / \mathrm{c}=0.35$ (left) and $\mathrm{w} / \mathrm{c}=0.45$. Circles indicate measurements made on specimens cured at $23{ }^{\circ} \mathrm{C}$ and squares indicate measurements made on specimens cured at $60{ }^{\circ} \mathrm{C}$. Filled symbols indicate the mean values for samples treated in the normal $105^{\circ} \mathrm{C}$ oven, and open symbols indicate the mean values for samples treated in the dry $105{ }^{\circ} \mathrm{C}$ oven. Error bars represent the range of two separate measurements on two samples. . . . . . . . . . . . . . . . . . . . 13

7 Differential mass loss as a function of temperature for cement 151 with $\mathrm{w} / \mathrm{c}=0.35$, cured at $23{ }^{\circ} \mathrm{C}$ to different ages and equilibrated at $105^{\circ} \mathrm{C}$ with "normal" atmospheric conditions (see text). . . . . . . . . . . . . . . . 14 
8 Differential mass loss as a function of temperature for cement 151 with w/c $=0.35$, cured at $23{ }^{\circ} \mathrm{C}$. The black curve was obtained after a $105{ }^{\circ} \mathrm{C}$ equilibration in ambient laboratory air, and the red curve was obtained after equilibration at the same temperature in dry and $\mathrm{CO}_{2}$-free air. . . . . . . . 15

9 Computer model (lines) and experimental results (points) for the heat of hydration of cement 151 (left) and cement 152. Error bars represent plus/minus one standard deviation in the values measured by about 20 laboratories. For cement $151 \beta=0.00031$, and for cement $152 \beta=0.00033 \ldots \ldots$. . . . . 16

10 Volume fraction of connected solids as a function of time predicted by VCCTL for cements 151 (left) and 152. The vertical dashed lines indicate the experimentally measured initial and final setting times as measured by the Vicat needle method. Error bars in the predictions at any time indicate the range of values predicted on two statistically identical microstructures. The values of the time conversion factor are indicated on the plots. . . . . . . . 17

11 Computer model (lines) and experimental results (points) for the compressive strength of cement 151 (left) and cement 152. The solid and dashed curves were made by calibrating the prefactor to the 3 - $\mathrm{d}$ and $7 \mathrm{~d}$ strength measurement, respectively. Error bars represent plus/minus one standard deviation in the values measured by about 200 laboratories. . . . . . . . . 18 


\section{List of Tables}

1 Comparison of estimated volume fractions of the four major clinker phases in cement 151, made by SEM image segmentation, quantitative X-ray diffraction (QXRD), and ASTM C150. All quantities are expressed on a mass percent basis. . . . . . . . . . . . . . . . . 5

2 Comparison of estimated volume fractions of the four major clinker phases in cement 152, made by SEM image segmentation, quantitative X-ray diffraction (QXRD), and ASTM C150. All quantities are expressed on a mass fraction percent basis. . . . . . . . . . . . . . . . . . .

3 Estimated phase data extracted from segmented SEM images for cement 151. The first four rows give area percentage and perimeter percentage of the four major clinker phases on a total clinker area basis, and the remaining rows give area percentage data for all solid phases on a total solids area basis. 7

4 Estimated phase data extracted from segmented SEM images for cement 151. The first four rows give area percentage and perimeter percentage of the four major clinker phases on a total clinker area basis, and the remaining rows give area percentage data for all solid phases on a total solids area basis. 8

5 Total and readily-soluble $\mathrm{K}_{2} \mathrm{O}$ and $\mathrm{Na}_{2} \mathrm{O}$ mass fraction percentages of cements 151 and 152, expressed on a total solids basis. Readily-soluble amounts are equated with concentrations in pore solution after $1 \mathrm{~h}$ of curing at $23{ }^{\circ}$ C . . . . . . . . . . . . . . . . . . . . . 8

6 Loss on ignition of initial powders and of pastes of cements 151 and 152 fully hydrated at room temperature. Values reported are the average of measurements on two different specimens, and the range of the two measurements was no more than $0.1 \%$ of the mean value. The final column is the estimate of LOI at full hydration based on quantitative X-ray analysis of the initial powder. . . . . . . . . . . . . . . . . 11 


\section{Introduction}

Twice each year, the Cement and Concrete Reference Laboratory (CCRL), located at the National Institute of Standards and Technology (NIST), issues two proficiency samples of Portland cement to be evaluated by hundreds of testing laboratories throughout the United States using ASTM standard test methods [2]. The chemical characteristics and performance properties of these cements are therefore extremely well documented [3], making them ideal systems against which to gauge the predictive capability of the NIST Virtual Cement and Concrete Testing Laboratory (VCCTL) computer models [4]. The key module of VCCTL used in this study is a collection of programs for creating and simulating the hydration of three-dimensional microstructures, based closely on the CEMHYD3D model of Bentz $[5,6]$. Five years ago, a comparison of predictions made by these models was made on CCRL proficiency samples 135 and 136, with respect to hydration kinetics, heat of hydration, and mortar strength development [7]. At that time, good agreement was observed between model predictions and experimental measurements of these properties.

In the intervening five years since that previous study, numerous extensions of the computer model have been made. Foremost among these changes are (1) the ability to estimate the $\mathrm{pH}$ of the capillary pore solution of a cement paste and to make the kinetics of hydration dependent upon $\mathrm{pH}$, and (2) incorporation of additional cement phases into the model, especially potassium sulfate, sodium sulfate, and free lime. In addition, over the years adjustments have been made to model parameters in an effort to better predict the behavior of a wider range of cements than those upon which the model was originally calibrated. Therefore, it seems desirable to conduct another study of the predictive capability of the newest version of VCCTL against two more recent CCRL proficiency samples.

In this report, scanning electron microscopy (SEM) images and quantititative phase analysis results for CCRL cements 151 and 152, issued in January 2004, will be presented and compared to the potential phase composition determined via ASTM C150 [2]. Additionally, VCCTL and supplemental experimental measurements will be applied to predicting the hydration kinetics, heat of hydration, and mortar strength development of the two cements. The latter two properties are compared to those measured by CCRL proficiency sample evaluation laboratories, while the hydration kinetics are compared to estimates of the degree of hydration made from loss-on-ignition measurements or from thermogramivetric analysis (TGA).

\section{Experimental Procedure}

Proficiency samples of CCRL cements 151 and 152 were obtained in January 2004. The samples were provided double-sealed in plastic bags. The particle size distribution of each cement was measured by laser diffraction $[8,9]$, and both cements were characterized by scanning electron microscopy and X-ray microanalysis. 


\subsection{Particle Size Distribution}

The particle size distributions (PSDs) of CCRL cements 151 and 152 were determined using laser diffraction through a dilute suspension of cement particles in isopropyl alcohol. The measurements were made using a Mastersizer instrument type HYDRO 2000S from Malvern Instruments, United Kingdom. ${ }^{1}$

For the measurements, a sample of cement powder having mass of about $0.1 \mathrm{~g}$ was introduced into a reservoir filled with about $0.5 \mathrm{~L}$ of anhydrous isopropyl alcohol. The actual amount of powder used was adjusted to obtain an optical transmission coefficient between 0.85 and 0.92 . The particle suspension was dispersed within the instrument using ultrasonic agitation and continuous mechanical stirring. The suspension was allowed sufficient time to thermally equilibrate, after which the diffraction data were collected and averaged over six sequential collection time intervals. The average particle size distributions obtained for both cement samples are plotted as probability density functions in Figure 1. The measured PSDs of the two cements are quite similar to each other; in fact, neither the mean particle diameter nor the median particle diameter, on a volume basis, differ by more than $1.0 \mu \mathrm{m}$ between the two cements. The mean Blaine finenesses reported for cements 151 and 152 are $379 \mathrm{~m}^{2} / \mathrm{kg}$ and $409 \mathrm{~m}^{2} / \mathrm{kg}$, respectively, as measured according to ASTM C204 [2] in the CCRL testing program [3]. The difference is consistent with the data in Fig. 1 showing cement 152 to be slightly finer than cement 151 .

\subsection{Microstructure Imaging and Segmentation}

The preparation techniques for specimens analyzed by SEM and X-ray microanalysis have been described in detail elsewhere $[1,10,11]$, so only a brief description will be provided here. Polished specimens are made by blending approximately $25 \mathrm{~g}$ of cement powder with about $5 \mathrm{~g}$ of an epoxy resin to form a viscous paste. The mixture is pressed into a cylindrical mold $\left(2.5 \mathrm{~cm}\right.$ diameter) and cured at $60{ }^{\circ} \mathrm{C}$ for $24 \mathrm{~h}$. The cured specimen is then cut to obtain a plane surface for imaging. The resulting saw marks are removed by a grinding with 400 grit sandpaper, followed by a finer grinding with 600 grit sandpaper. Final polishing is performed on a lap wheels with $(6 \mu \mathrm{m}, 3 \mu \mathrm{m}, 1 \mu \mathrm{m}$, and $0.25 \mu$ msequentially) diamond paste for $30 \mathrm{~s}$ each. After each polishing, the specimen is cleaned with a cloth. After the final polishing step, residual polishing compound is removed with ethanol, and the specimen is then coated with carbon to provide a conductive surface.

The polished specimen is placed in the SEM viewing chamber, and both backscattered electrons and X-rays are collected. Typical accelerating voltage and probe current for the backscattered electron images are $12 \mathrm{kV}$ and $2 \mathrm{nA}$, respectively. The probe current is increased to about $10 \mathrm{nA}$ for X-ray microanalysis, and X-ray element maps are collected for $\mathrm{Ca}, \mathrm{Si}, \mathrm{Al}, \mathrm{Fe}, \mathrm{S}, \mathrm{K}, \mathrm{Na}$, and $\mathrm{Mg}$. The element maps all are collected on the same

\footnotetext{
${ }^{1}$ Certain commercial instruments are identified in this report to specify the experimental procedure. In no case does such identification imply endorsement by the National Institute of Standards and Technology, nor does it indicate that the equipment is necessarily the best available for the purpose.
} 


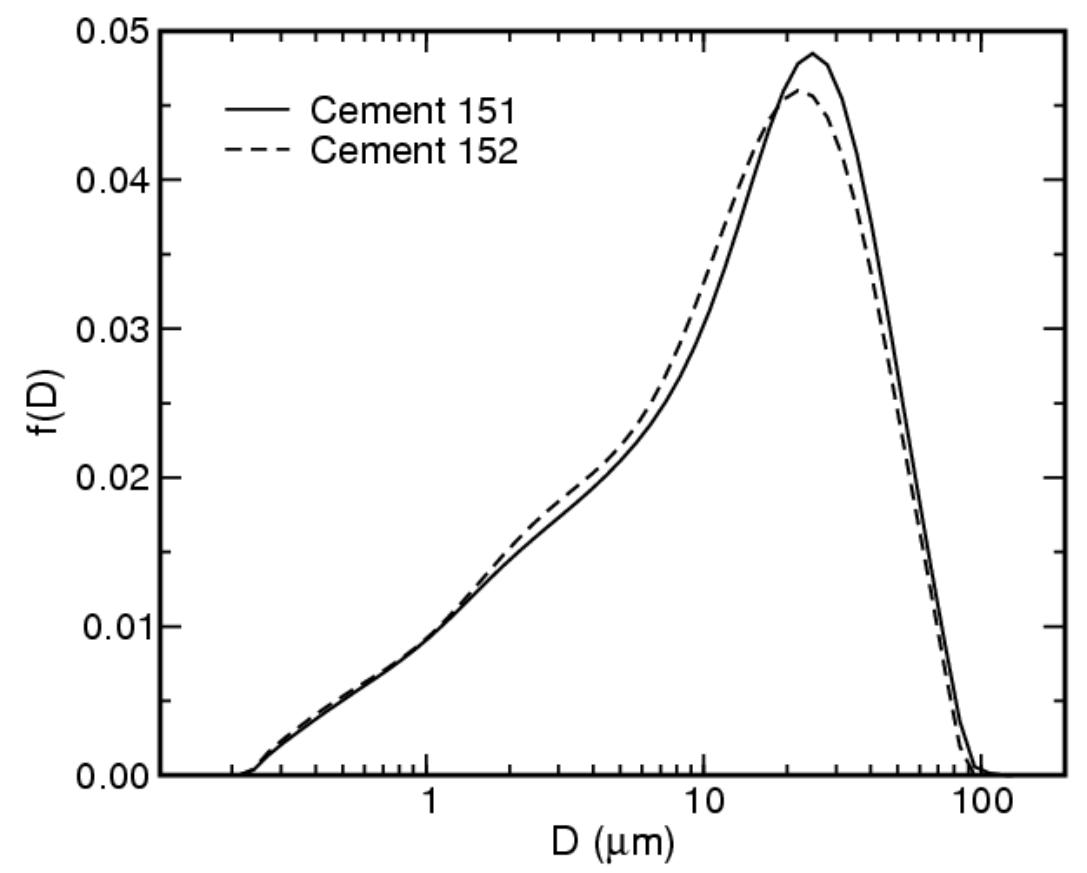

Figure 1: Particle size distributions, plotted as probability density functions, measured for CCRL cements 151 and 152 using laser diffraction from a dilute suspension of particles in anhydrous isopropyl alcohol.

image field, so they can be overlayed to form a composite image of the microstructure with element-specific information at each pixel. Examples of these composite X-Ray images for cements 151 and 152 are shown in Fig. 2. In these images, three different X-ray signal intensities $(\mathrm{Ca}, \mathrm{Si}$, and $\mathrm{Al})$ have been mapped into the three color signal channels (red, green, and blue), respectively.

The combined X-ray element maps for a given image field were used to determine the distribution of mineral phases by traversing a decision tree for each pixel in the image. The decision tree is shown as a flow chart in Fig. 3. In the figure, as elsewhere in this report, standard cement chemistry notation is used: $\mathrm{C}=\mathrm{CaO}, \mathrm{S}=\mathrm{SiO}_{2}, \mathrm{~A}=\mathrm{Al}_{2} \mathrm{O}_{3}$, and $\mathrm{F}=\mathrm{Fe}_{2} \mathrm{O}_{3}$.

After the decision tree is applied, pixel-by-pixel, to the image, the resulting segmented image will still contain a substantial amount of random noise carried over from the noise of the X-ray element maps. The image quality is improved by sequentially filtering the segmented image through three noise-reducing algorithms. By the first algorithm, all isolated solid pixels surrounded by void space are converted to void space. In the second algorithm, all isolated void space surrounded by solids are converted to the majority solid phase in the neighboring pixels. The third algorithm is a median filter [12], which replaces each solid pixel by the majority solid phase in the surrounding neighborhood, which typically is taken to be a $5 \times 5$-pixel square centered on the pixel in question.

Examples of final segmented images of cements 151 and 152, following the noise filtering procedure just described, are shown in Fig. 4. Seven separate image fields for cement 

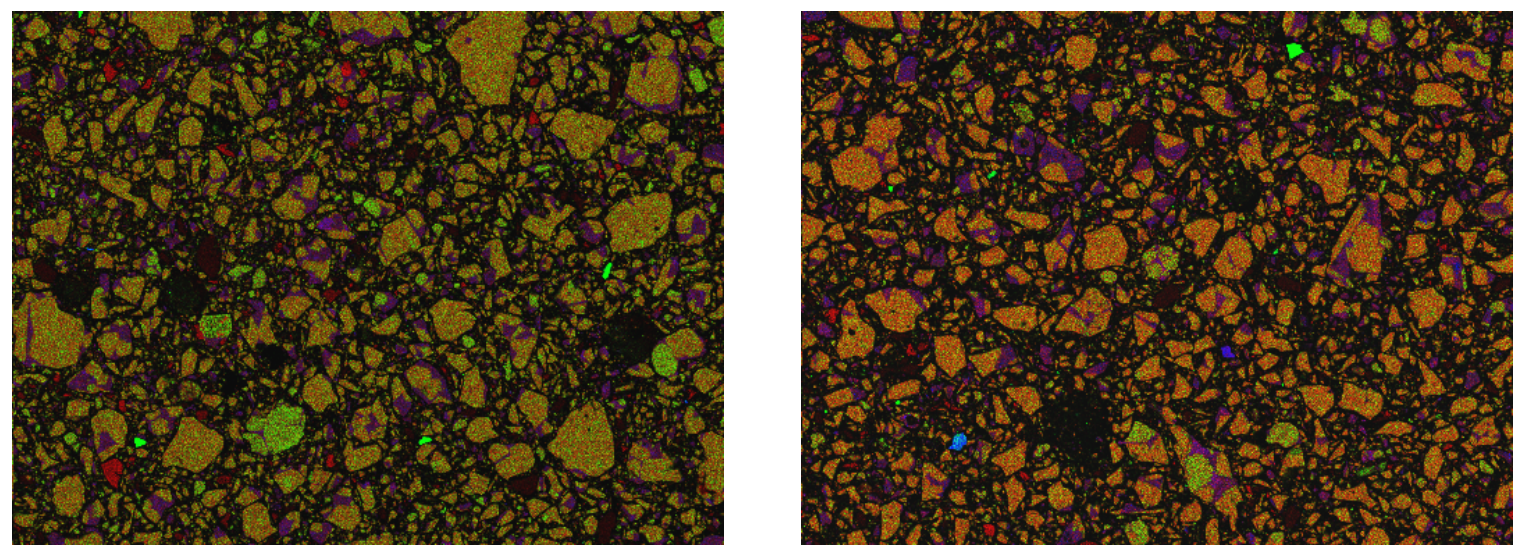

Figure 2: Composite RGB images of cement 151 (left) and cement 152 (right). The degree of red is proportional to the $\mathrm{Ca} \mathrm{X}$-ray signal intensity, green to that for $\mathrm{Si}$, and blue to that for Al. Therefore, shades of yellow correspond to (red/green or $\mathrm{Ca} / \mathrm{Si}$ ) calcium silicate phases and shades of purple correspond to (red/blue or $\mathrm{Ca} / \mathrm{Al}$ ) calcium aluminate phases. Black regions are epoxy-filled pore space. The image field dimensions are $256 \mu \mathrm{m} \times$ $200 \mu \mathrm{m}$.

151 and six separate image fields for cement 152 were acquired and segmented as described in this section.

\subsection{Stereological Analysis}

The final images of cements 151 and 152, resulting from the procedures described in Section 2.2, were analyzed quantitatively to determine properties of interest for modeling the 3-D microstructure and hydration. These properties include the area fraction and surface perimeter fraction of the various mineral phases, as well as their spatial distribution. The volume fraction of each phase determines the extent of each type of cement hydration that can occur, and the surface area fraction of each phase influences the rate at which dissolution of that phase into the adjacent water-filled porosity can proceed. Assuming that the microstructure is isotropic, the area fraction of each phase in the 2-D image will equal its volume fraction in a 3-D microstructure. Similarly, the surface perimeter fraction in 2-D will equal the surface area fraction in 3-D for an isotropic system. Simple pixel counting and examination of the neighborhood surrounding each pixel are used to determine the 2-D area fraction and surface perimeter fraction of phases in images like those in Fig. 4.

For both cements 151 and 152, the clinker compositions averaged from a collection of final cement images have been compared to estimates made both by bulk quantitative X-ray diffraction (QXRD) [13] and by cement oxide composition using ASTM C150 [2]. The estimates are shown in Table 1 for cement 151 and in Table 2 for cement 152.

Volume fractions of all the solid cement phases detected in the final segmented images are shown in Tables 3 and 4 for cements 151 and 152, respectively. In these tables, the 


\begin{tabular}{crcr}
\hline Phase & \multicolumn{1}{c}{ SEM } & QXRD & \multicolumn{1}{c}{ Bogue } \\
\hline $\mathrm{C}_{3} \mathrm{~S}$ & $62.2 \pm 3.9^{a}$ & 59.5 & $70.9 \pm 4.3^{b}$ \\
$\mathrm{C}_{2} \mathrm{~S}$ & $19.1 \pm 3.6$ & 20.8 & $9.7 \pm 3.8$ \\
$\mathrm{C}_{3} \mathrm{~A}$ & $4.4 \pm 2.3$ & 5.6 & $7.9 \pm 0.5$ \\
$\mathrm{C}_{4} \mathrm{AF}$ & $14.3 \pm 2.3$ & 14.1 & $11.6 \pm 0.2$ \\
\hline
\end{tabular}

${ }^{a}$ Uncertainty expressed as plus/minus one standard deviation calculated from a sample of seven images.

${ }^{b}$ Uncertainty expressed as plus/minus one standard deviation calculated from over 150 values.

Table 1: Comparison of estimated volume fractions of the four major clinker phases in cement 151, made by SEM image segmentation, quantitative X-ray diffraction (QXRD), and ASTM C150. All quantities are expressed on a mass percent basis.

\begin{tabular}{crcc}
\hline Phase & \multicolumn{1}{c}{ SEM } & QXRD & ASTM C150 \\
\hline \hline $\mathrm{C}_{3} \mathrm{~S}$ & $73.3 \pm 0.8^{a}$ & 72.1 & $61.5 \pm 4.5^{b}$ \\
$\mathrm{C}_{2} \mathrm{~S}$ & $9.6 \pm 0.6$ & 8.9 & $10.8 \pm 4.0$ \\
$\mathrm{C}_{3} \mathrm{~A}$ & $12.4 \pm 0.8$ & 11.7 & $11.0 \pm 0.5$ \\
$\mathrm{C}_{4} \mathrm{AF}$ & $4.7 \pm 0.4$ & 7.3 & $7.3 \pm 0.2$ \\
\hline
\end{tabular}

${ }^{a}$ Uncertainty expressed as plus/minus one standard deviation calculated from a sample of six images.

${ }^{b}$ Uncertainty expressed as plus/minus one standard deviation calculated from over 150 values.

Table 2: Comparison of estimated volume fractions of the four major clinker phases in cement 152, made by SEM image segmentation, quantitative X-ray diffraction (QXRD), and ASTM C150. All quantities are expressed on a mass fraction percent basis. 


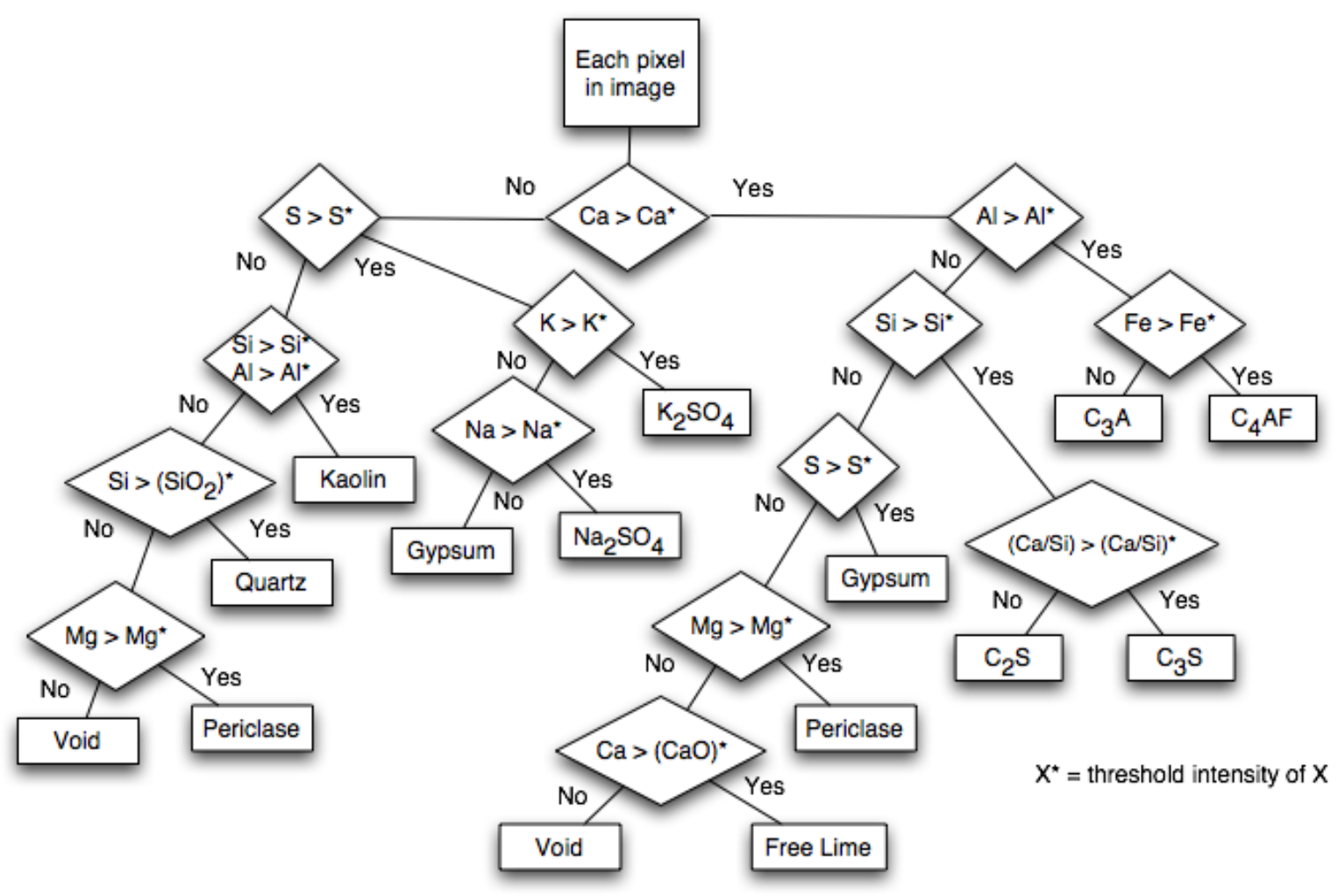

Figure 3: Decision tree for pixel-by-pixel segmentation of a cement image into its mineral components. Conventional cement chemistry notation is used: $\mathrm{C}_{3} \mathrm{~S}$ denotes tricalcium silicate, $\mathrm{C}_{2} \mathrm{~S}$ denotes dicalcium silicate, $\mathrm{C}_{3} \mathrm{~A}$ denotes tricalcium aluminate, and $\mathrm{C}_{4} \mathrm{AF}$ denotes tetracalcium aluminoferrite. Adapted from [1].

first four rows give the area fractions and perimeter of the four major clinker phases on a total clinker basis. The remaining rows provide the volume fractions of all the solid cement phases on a total solids basis.

The detection of $\mathrm{K}_{2} \mathrm{SO}_{4}$, and especially $\mathrm{Na}_{2} \mathrm{SO}_{4}$, is difficult and somewhat unreliable using SEM/X-ray microanalysis because the quantities of these salts are so small and usually appear in very small domains within the cement. Therefore, ion chromatography (IC) was used to estimate the readily soluble alkali oxide content in both cements. Pastes of each cement were prepared and allowed to cure for $1 \mathrm{~h}$, after which the capillary pore solution was extracted by centrifuging the specimens for five minutes. A diluted sample of the pore solution was analyzed for $\mathrm{Na}^{+}$and $\mathrm{K}^{+}$cations. The signals obtained from the diluted pore solution were compared against precisely diluted solutions of $\mathrm{KCl}$ and $\mathrm{NaCl}$ to determine the concentrations of $\mathrm{Na}^{+}$and $\mathrm{K}^{+}$. The results are shown in Table 5 .

The spatial distribution of clinker phases in the microstructure is quantified by calculating the two-point correlation functions on the images in Fig. 4. On an $M \times N$ digital 


\begin{tabular}{crr}
\hline Phase & \multicolumn{1}{c}{ Area } & \multicolumn{1}{c}{ Perimeter } \\
\hline \hline $\mathrm{C}_{3} \mathrm{~S}$ & $63.6 \pm 3.7^{a}$ & $55.6 \pm 4.6$ \\
$\mathrm{C}_{2} \mathrm{~S}$ & $19.1 \pm 3.6$ & $26.0 \pm 5.7$ \\
$\mathrm{C}_{3} \mathrm{~A}$ & $4.8 \pm 2.4$ & $5.9 \pm 2.9$ \\
$\mathrm{C}_{4} \mathrm{AF}$ & $12.6 \pm 2.1$ & $12.5 \pm 2.1$ \\
\hline $\mathrm{C}_{3} \mathrm{~S}$ & $58.9 \pm 3.9$ & \\
$\mathrm{C}_{2} \mathrm{~S}$ & $17.6 \pm 3.3$ & \\
$\mathrm{C}_{3} \mathrm{~A}$ & $4.4 \pm 2.3$ & \\
$\mathrm{C}_{4} \mathrm{AF}$ & $11.7 \pm 1.8$ & \\
$\mathrm{CaSO}$ & \\
$\mathrm{CaO} \cdot x \mathrm{H}_{2} \mathrm{O}$ & $5.6 \pm 1.0$ & \\
$\mathrm{SiO}_{2}$ & $0.7 \pm 0.2$ & \\
$\mathrm{~K}_{2} \mathrm{SO}_{4}$ & $0.4 \pm 0.1$ & \\
$\mathrm{Na}_{2} \mathrm{SO}_{4}$ & $0.4 \pm 0.1$ & \\
$\mathrm{Kaolin}_{\mathrm{Mg}_{x} \mathrm{Ca}_{1-x} \mathrm{O}}$ & $0.0 \pm 0.0^{b}$ & \\
$\mathrm{M}_{2}$ & $0.1 \pm 0.2$ & \\
\hline
\end{tabular}

${ }^{a}$ Uncertainty expressed as plus/minus one standard deviation calculated from a sample of seven images.

${ }^{b} \mathrm{Na}_{2} \mathrm{SO}_{4}$ was not detected in any of the seven image fields, although QXRD data implies that it is present in small quantities.

Table 3: Estimated phase data extracted from segmented SEM images for cement 151. The first four rows give area percentage and perimeter percentage of the four major clinker phases on a total clinker area basis, and the remaining rows give area percentage data for all solid phases on a total solids area basis. 


\begin{tabular}{crr}
\hline Phase & \multicolumn{1}{c}{ Area } & Perimeter \\
\hline \hline $\mathrm{C}_{3} \mathrm{~S}$ & $73.4 \pm 1.0^{a}$ & $68.7 \pm 2.1$ \\
$\mathrm{C}_{2} \mathrm{~S}$ & $9.4 \pm 0.6$ & $13.4 \pm 1.2$ \\
$\mathrm{C}_{3} \mathrm{~A}$ & $13.1 \pm 0.8$ & $13.9 \pm 1.2$ \\
$\mathrm{C}_{4} \mathrm{AF}$ & $4.1 \pm 0.3$ & $4.1 \pm 0.5$ \\
\hline $\mathrm{C}_{3} \mathrm{~S}$ & $66.4 \pm 0.7$ & \\
$\mathrm{C}_{2} \mathrm{~S}$ & $8.5 \pm 0.6$ & \\
$\mathrm{C}_{3} \mathrm{~A}$ & $11.8 \pm 0.8$ & \\
$\mathrm{C}_{4} \mathrm{AF}$ & $3.7 \pm 0.3$ & \\
$\mathrm{CaSO}_{4} \cdot x \mathrm{H}_{2} \mathrm{O}$ & $6.0 \pm 0.7$ & \\
$\mathrm{CaO}_{\mathrm{Sa}}$ & $0.9 \pm 0.1$ & \\
$\mathrm{SiO}_{2}$ & $0.5 \pm 0.2$ & \\
$\mathrm{~K}_{2} \mathrm{SO}_{4}$ & $1.0 \pm 0.3$ & \\
$\mathrm{Na}_{2} \mathrm{SO}_{4}$ & $0.1 \pm 0.3$ & \\
$\mathrm{Kaolin}_{\mathrm{Mg}_{x} \mathrm{Ca}_{1-x} \mathrm{O}}$ & $0.1 \pm 0.1$ & \\
\hline
\end{tabular}

${ }^{a}$ Uncertainty expressed as plus/minus one standard deviation calculated from a sample of six images.

Table 4: Estimated phase data extracted from segmented SEM images for cement 151. The first four rows give area percentage and perimeter percentage of the four major clinker phases on a total clinker area basis, and the remaining rows give area percentage data for all solid phases on a total solids area basis.

\begin{tabular}{ccccc}
\hline & \multicolumn{2}{c}{ Cement 151 } & \multicolumn{2}{c}{ Cement 152 } \\
Phase & Total & Readily Soluble & Total & Readily Soluble \\
\hline \hline $\mathrm{K}_{2} \mathrm{O}$ & $0.320 \pm 0.019^{a}$ & 0.250 & $0.500 \pm 0.023$ & 0.250 \\
$\mathrm{Na}_{2} \mathrm{O}$ & $0.269 \pm 0.029$ & 0.086 & $0.191 \pm 0.027$ & 0.033 \\
\hline
\end{tabular}

\footnotetext{
${ }^{a}$ Uncertainty expressed as plus/minus one standard deviation of the measurements by about 150 laboratories.

Table 5: Total and readily-soluble $\mathrm{K}_{2} \mathrm{O}$ and $\mathrm{Na}_{2} \mathrm{O}$ mass fraction percentages of cements 151 and 152, expressed on a total solids basis. Readily-soluble amounts are equated with concentrations in pore solution after $1 \mathrm{~h}$ of curing at $23{ }^{\circ} \mathrm{C}$.
} 

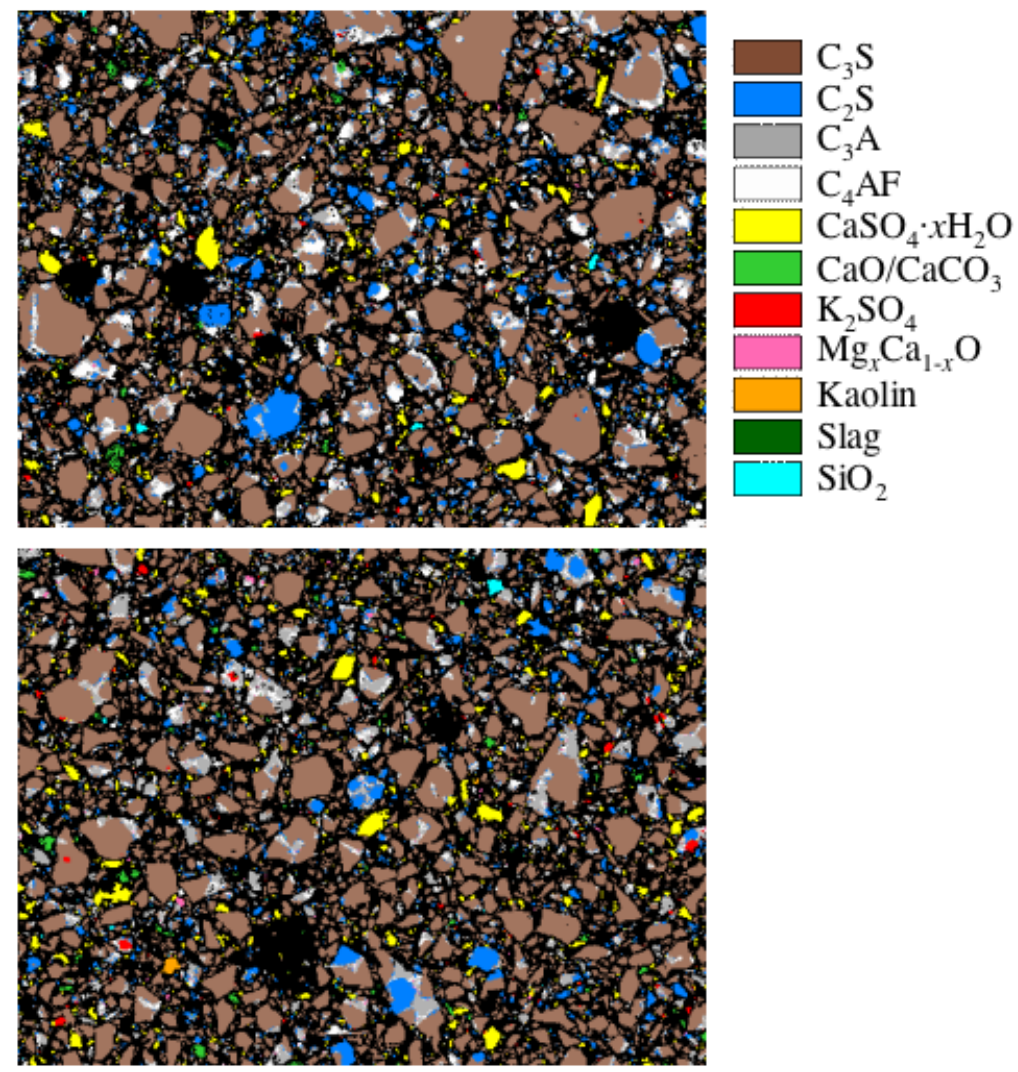

Figure 4: Final processed images of cement 151 (top) and cement 152 (bottom). The color coding of each mineral phase is keyed to the accompanying legend. The image field dimensions are $256 \mu \mathrm{m} \times 200 \mu \mathrm{m}$.

image field, the two-point correlation function, $S_{p}(x, y)$, for any phase $p$ is given by:

$$
S_{p}(x, y)=\sum_{i=1}^{M-x} \sum_{j=1}^{N-y} \frac{I_{p}(i, j) \cdot I_{p}(i+x, y+j)}{(M-x)(N-y)} \quad \begin{aligned}
& 1 \leq x \leq M \\
& 1 \leq y \leq N
\end{aligned}
$$

where $I_{p}(x, y)=1$ if the pixel at location $(x, y)$ contains the phase or phases designated by $p$, and $I_{p}(x, y)=0$ otherwise. Again assuming that the microstructure is isotropic, $S_{p}(x, y)$ may be transformed to a function of distance only, $S_{p}(r)$, where $r=\sqrt{x^{2}+y^{2}}$. Correlation functions for isotropic materials are identical in 2-D and 3-D, so the correlation functions calculated on the final images in Fig. 4 can be used directly to reconstruct 3-D microstructures with the same statistical spatial distribution of phases. The value of $S_{p}(0)$ is equal to the area fraction of phase $p$ in the image, and the surface perimeter $L_{p}$ per unit area $A_{p}$ of phase $p$ is given by the expression

$$
\frac{L_{p}}{A_{p}}=-\left.4 \frac{\mathrm{d} S_{p}(r)}{\mathrm{d} r}\right|_{r=0}
$$


In other words, knowledge of $S_{p}(r)$ for each phase of interest is sufficient to reconstruct a 3-D microstructure for which each phase has volume fraction and surface area fraction statistically equal to those measured on the actual powder. Reconstructing finer details of a microstructure would require higher-order correlation functions [14], but higher-order correlation functions are considerably more difficult to obtain, and experience has shown that the two-point correlations functions contain sufficient information to capture the major microstructural effects.

\subsection{Estimating Degree of Hydration}

The degree of hydration of paste specimens made from cements 151 and 152 was estimated by measurement of the loss on ignition (LOI) of the paste after any hydration age of interest. Cement pastes were prepared with water-to-cement mass ratios (w/c) of 0.35 or 0.45 . Approximately $300 \mathrm{~g}$ of cement powder and the necessary mass of water were mixed together in a high-shear mixer for $2.5 \mathrm{~min}$. After mixing, specimens of about $10 \mathrm{~g}$ each were placed in 30-mL plastic vials with about $2 \mathrm{~mL}$ of deionized water added on top to maintain saturated curing conditions. The vials were then capped and stored in water baths at either $23{ }^{\circ} \mathrm{C}$ or $60{ }^{\circ} \mathrm{C}$. The temperature of each water bath was maintained to within $1{ }^{\circ} \mathrm{C}$.

Hydration of a specimen was interrupted by grinding and double flushing with anhydrous ethanol. LOI was measured after ages of 3 h, 6 h, 12 h, 24 h, 48 h, 168 h (7 d), $336 \mathrm{~h}$ (14 d), $672 \mathrm{~h} \mathrm{(28} \mathrm{d),} \mathrm{or} 1344 \mathrm{~h}$ (56 d). To measure LOI, the specimens were removed

from the plastic vial and ground to a coarse powder with an alumina mortar and pestle. The powder was then vacuum filtered twice with anhydrous methanol to remove free water. The resultant powder was then divided approximately in half into two ceramic crucibles and placed in an oven at $105{ }^{\circ} \mathrm{C}$. Two different atmospheres were used in the ovens. The first atmosphere consisted of static ambient laboratory air with a dew point of about $13{ }^{\circ} \mathrm{C}$ and $\mathrm{CO}_{2}$ content of approximately $50 \mu \mathrm{Pa} / \mathrm{Pa}(50 \mathrm{ppm})$. The other atmosphere consisted of slowly flowing air (about $4 \mathrm{~cm}^{3} / \mathrm{min}$ ) with a dew point of $-70{ }^{\circ} \mathrm{C}$ and a $\mathrm{CO}_{2}$ content less than $1 \mu \mathrm{Pa} / \mathrm{Pa}(1 \mathrm{ppm})$. Hereafter, these two atmospheres will be denoted as "Normal" and "Dry", respectively. After about $20 \mathrm{~h}$, the specimens were removed, weighed, and then placed in a furnace that was rapidly heated to $1000{ }^{\circ} \mathrm{C}$ and held for at least $4 \mathrm{~h}$. Afterward, the specimens were cooled quickly and the mass measured immediately. The LOI was calculated as the average difference between the measured masses at $105{ }^{\circ} \mathrm{C}$ and $1000{ }^{\circ} \mathrm{C}$. This experimental technique is similar to that used to measure the non-evaporable water content of a cement paste [15], except that the latter procedure uses D-drying instead of the $105^{\circ} \mathrm{C}$ heat treatment.

To convert LOI measurements to estimated degrees of hydration, $\alpha$, it is necessary to measure the LOI of a specimen that has been fully hydrated, i.e. for which all the anhydrous cement has been converted to hydration products. Therefore, pastes of cement 151 and 152 were prepared with $\mathrm{w} / \mathrm{c}=3.0$, and these pastes were sealed in a plastic bottle and continuously mixed by ball milling with stainless steel media for $28 \mathrm{~d}$ at room temperature. Afterward, the LOI of these pastes were measured by the procedures just described. The 


\begin{tabular}{cccccr}
\hline \multirow{2}{*}{ Cement } & \multicolumn{2}{c}{ Powder (g/g cement) } & \multicolumn{2}{c}{ Fully Hydrated (g/g cement) } & \\
& Normal & Dry & Normal & Dry & QXRD \\
\hline \hline 151 & 0.0108 & 0.0092 & 0.2633 & 0.2018 & 0.245 \\
152 & 0.0097 & 0.0088 & 0.2686 & 0.1940 & 0.238 \\
\hline
\end{tabular}

Table 6: Loss on ignition of initial powders and of pastes of cements 151 and 152 fully hydrated at room temperature. Values reported are the average of measurements on two different specimens, and the range of the two measurements was no more than $0.1 \%$ of the mean value. The final column is the estimate of LOI at full hydration based on quantitative $\mathrm{X}$-ray analysis of the initial powder.

values of LOI for the dry ignited powders and fully-hydrated cements are given in Table 6 . Also included in the table is an estimate of the LOI at full hydration based on QXRD of the initial powders. The degree of hydration for all the pastes was then estimated by dividing the LOI of the paste by the LOI of the fully hydrated paste. Unless mentioned otherwise, the estimate from QXRD was used to convert LOI measurements to degree of hydration.

\subsection{Thermogravimetry}

Thermogravimetric analysis (TGA) was undertaken on certain pastes cured to different ages to determine the major sources of mass loss between $105^{\circ} \mathrm{C}$ and $1000{ }^{\circ} \mathrm{C}$. For this type of measurement, a specimen was equilibrated at $105^{\circ} \mathrm{C}$ for $20 \mathrm{~h}$ to $24 \mathrm{~h}$ in either the normal or dry environments, as described in the previous section. Following this treatment, the specimen was transferred to the TGA apparatus and heated at $5{ }^{\circ} \mathrm{C} / \mathrm{min}$ to $1000{ }^{\circ} \mathrm{C}$ in a $\mathrm{N}_{2}$ atmosphere. Temperature and mass data were recorded about once every six seconds.

\section{Results}

\subsection{Hydration Kinetics}

Figure 5 shows plots of the model predictions and experimental results for degree of hydration for cement 151 at $\mathrm{w} / \mathrm{c}=0.35$ and $\mathrm{w} / \mathrm{c}=0.45$. As shown in the figure, a time conversion factor $\beta=0.00036 \mathrm{~h} / \mathrm{cycle}^{2}$ was used at $\mathrm{w} / \mathrm{c}=0.35$ and $\beta=0.00027 \mathrm{~h} / \mathrm{cycle}^{2}$ was used at $\mathrm{w} / \mathrm{c}=0.45$. These values of $\beta$ were chosen to give the best fit to the experimental data at $23{ }^{\circ} \mathrm{C}$ using the normal $105{ }^{\circ} \mathrm{C}$ oven treatment. The match between prediction and experiment is quite good for the $\mathrm{w} / \mathrm{c}=0.35$ specimens cured at $23{ }^{\circ} \mathrm{C}$ using the normal $105{ }^{\circ} \mathrm{C}$ oven. Even for $w / c=0.45$, the fit between model and experiment at $23{ }^{\circ} \mathrm{C}$ is reasonably good, although the predictions at early ages $(<48 \mathrm{~h})$ are too low.

The measured degrees of hydration are significantly less when the specimens are treated at $105{ }^{\circ} \mathrm{C}$ in the dry oven than when they are treated at the same temperature in the normal oven, and the differences increase with increasing age. This is true of both cements, at both curing temperatures, and at each w/c ratio. These lower values are expected because of the 

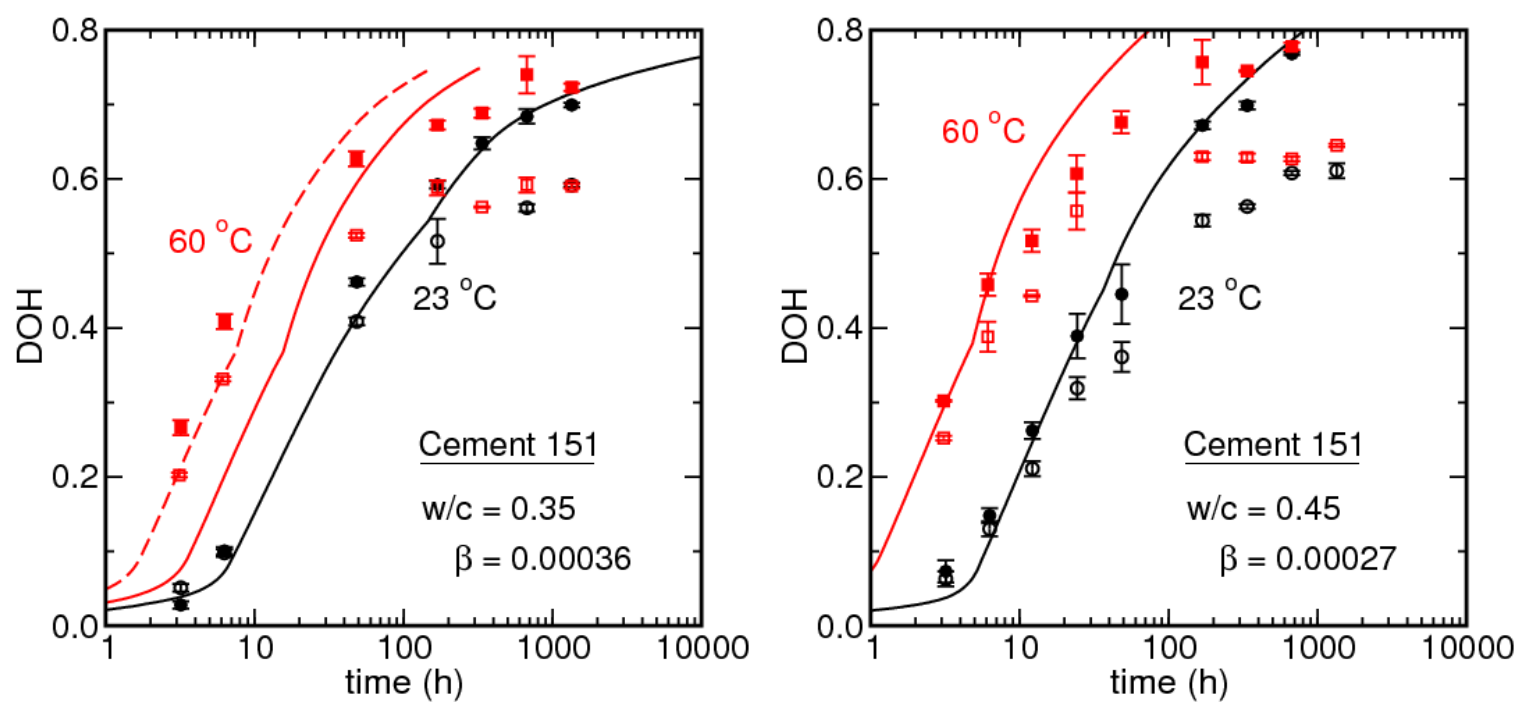

Figure 5: Computer model (lines) and experimental results (points) for degree of hydration of cement 151 with w/c $=0.35$ (left) and w/c $=0.45$ (right). Circles indicate mean values measured for specimens cured at $23{ }^{\circ} \mathrm{C}$ and squares indicate mean values measured for specimens cured at $60{ }^{\circ} \mathrm{C}$. Filled symbols indicate measurements made with the normal $105{ }^{\circ} \mathrm{C}$ oven, and open symbols indicate measurements made with the dry $105{ }^{\circ} \mathrm{C}$ oven. Error bars on experimental data represent the range of two measurements made on two samples. The dashed curve in each plot is the model prediction for curing at $60{ }^{\circ} \mathrm{C}$ when an effective activation energy of $56.3 \mathrm{~kJ} / \mathrm{mole}$ is used.

harsher drying conditions in the dry $105^{\circ} \mathrm{C}$ oven. If the "Dry" value for degree of hydration of the fully hydrated cement, shown in Table 6, is used to convert the LOI measurements to degree of hydration, the data using the dry oven lie much more closely to the data acquired using the normal oven.

At a curing temperature of $60{ }^{\circ} \mathrm{C}$ the model predictions and experimental data do not agree nearly as well as they do at $23{ }^{\circ} \mathrm{C}$, especially at later ages. VCCTL accounts for curing temperature through an exponential, Arrhenius-like, correction factor to the value of the time conversion factor, $\beta$. The default value of the effective "activation energy" used in this term is $40 \mathrm{~kJ} /$ mole. Modifying this value to $56.3 \mathrm{~kJ} / \mathrm{mole}$ changes the predictions to those shown in the dashed line of Fig. 5, which agree much better with the early-age measurements at $60{ }^{\circ} \mathrm{C}$, although the later-age predictions are poorer. The fact that one cannot improve the fit at both early and late ages simultaneously indicates that the several assumptions used by the model to mimic the kinetics of hydration are inadequate or perhaps invalid. Chief among these assumptions are (1) that time scales parabolically with the number of computational cycles, and (2) that the activation energy is independent of the different kinetic mechanisms that control the rate of hydration during different regimes of the microstructural development of cement paste. This latter point is particularly important because one may readily expect the rate-controlling mechanism to change at least once 
throughout the hydration of a cement paste.

Figure 6 shows plots of the model predictions and experimental results for degree of hydration for cement 152 at $\mathrm{w} / \mathrm{c}=0.35$ and $\mathrm{w} / \mathrm{c}=0.45$. As shown in the figure, a time conversion factor $\beta=0.00032 \mathrm{~h} /$ cycle $^{2}$ was used at $\mathrm{w} / \mathrm{c}=0.35$ and $\beta=0.00034 \mathrm{~h} / \mathrm{cycle}^{2}$ was used at $\mathrm{w} / \mathrm{c}=0.45$. As for cement 151 , the values of $\beta$ for cement 152 were chosen to give the best fit to the experimental data at $23{ }^{\circ} \mathrm{C}$ using the normal $105{ }^{\circ} \mathrm{C}$ oven treatment.
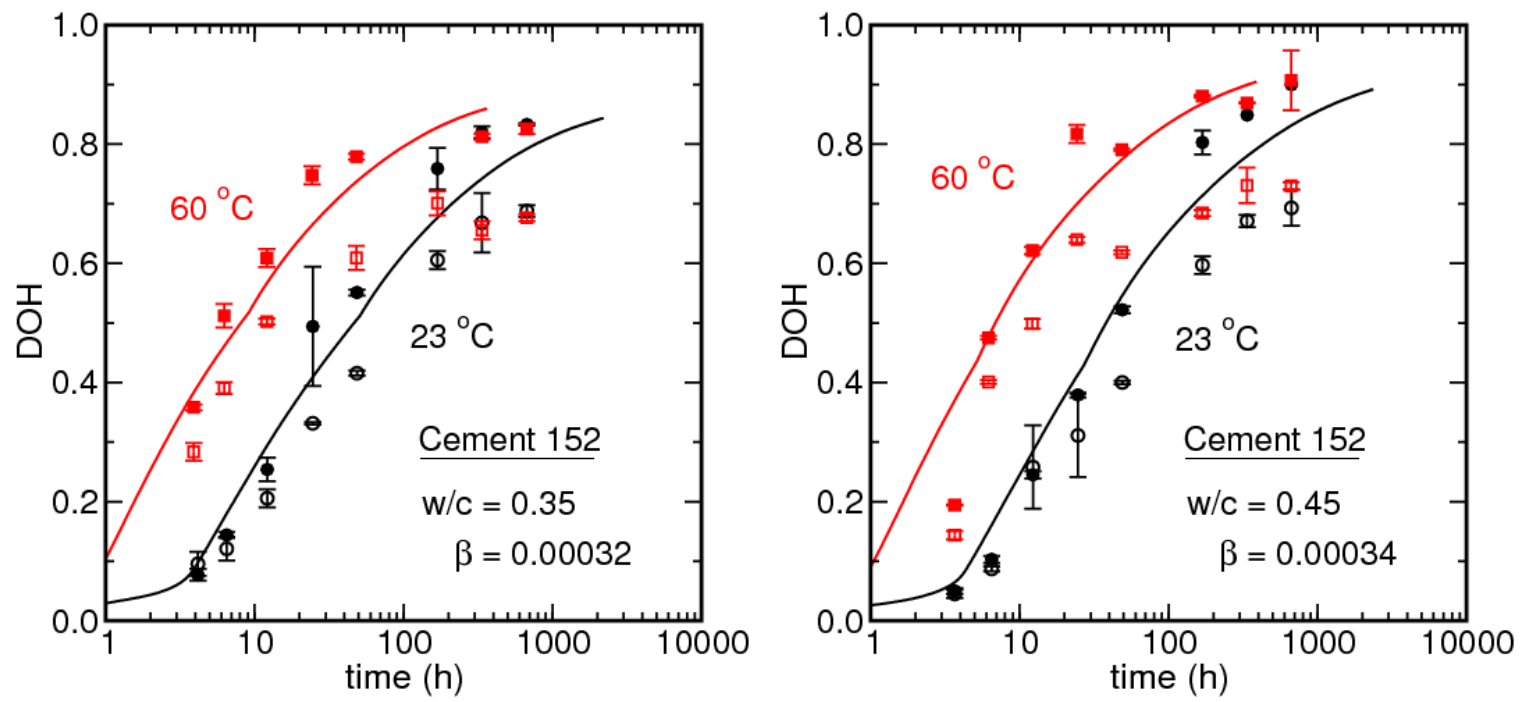

Figure 6: Computer model (lines) and experimental results (points) for degree of hydration of cement 152 with $w / c=0.35$ (left) and $w / c=0.45$. Circles indicate measurements made on specimens cured at $23{ }^{\circ} \mathrm{C}$ and squares indicate measurements made on specimens cured at $60{ }^{\circ} \mathrm{C}$. Filled symbols indicate the mean values for samples treated in the normal $105^{\circ} \mathrm{C}$ oven, and open symbols indicate the mean values for samples treated in the dry $105{ }^{\circ} \mathrm{C}$ oven. Error bars represent the range of two separate measurements on two samples.

In general, the same trends are observed in Fig. 6 for cement 152 as for cement 151 (Fig. 5). The predictions for curing at $23{ }^{\circ} \mathrm{C}$ fit experimental observations much better than the predictions for curing at $60^{\circ} \mathrm{C}$, although, in contrast to the predictions for cement 151 , the default value of $40 \mathrm{~kJ} / \mathrm{mole}$ for the effective activation energy appears to fit the early age data at $60{ }^{\circ} \mathrm{C}$. At $23{ }^{\circ} \mathrm{C}$, the only major deviation of the model predictions from experimental measurement is for $\mathrm{w} / \mathrm{c}=0.45$ at later ages, for which the predictions are too low.

\subsection{Thermogravimetry}

As described earlier, LOI measurements are made by subtracting the mass of a specimen ignited at $1000{ }^{\circ} \mathrm{C}$ from the mass of a specimen equilibrated at $105^{\circ} \mathrm{C}$. As Figures 5 and 6 show, the degree of hydration measured on a paste depends on the moisture, and possibly $\mathrm{CO}_{2}$ content, in the atmosphere during the $105{ }^{\circ} \mathrm{C}$ treatment. To clarify the cause of this 
behavior, a more detailed examination of the mass loss between $105{ }^{\circ} \mathrm{C}$ and $1000{ }^{\circ} \mathrm{C}$ was obtained by thermogravimetric analysis (TGA).

Fig. 7 plots the relative mass loss as a function of temperature for cement 151 cured at $23{ }^{\circ} \mathrm{C}$ to several different hydration ages. The data are plotted in terms of the "rate" of mass change, $\mathrm{d} m / \mathrm{d} T$, where $m$ is mass and $T$ is temperature. For all these curves, the normal atmosphere was used during the treatment at $105{ }^{\circ} \mathrm{C}$. The main features of this plot are a peak between $450{ }^{\circ} \mathrm{C}$ and $550{ }^{\circ} \mathrm{C}$ that increases with hydration age, and a smaller peak at about $700{ }^{\circ} \mathrm{C}$ which remains roughly the same height with hydration age.

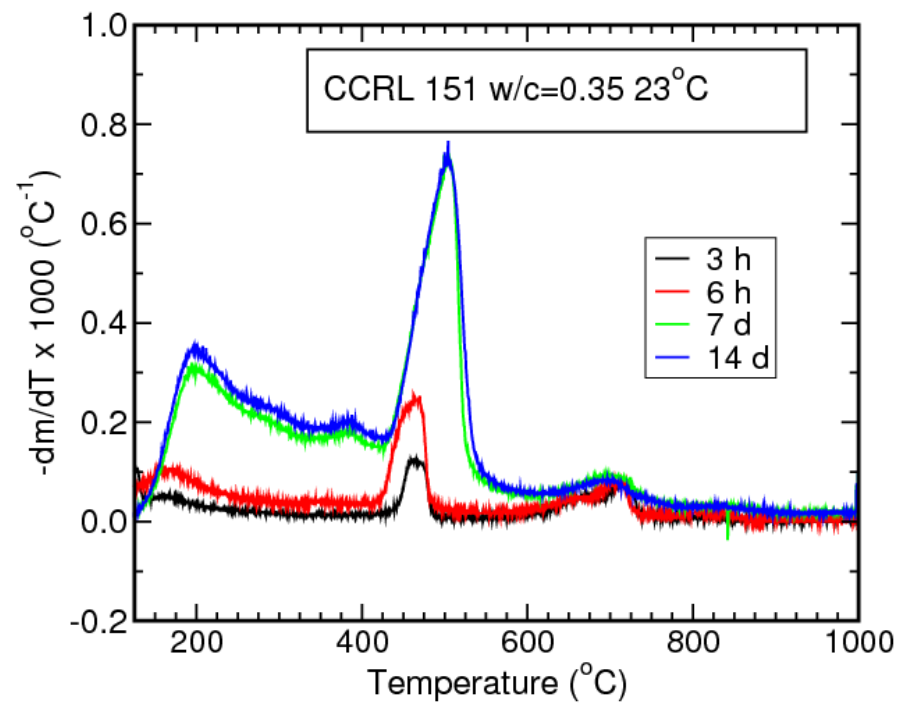

Figure 7: Differential mass loss as a function of temperature for cement 151 with w/c $=0.35$, cured at $23{ }^{\circ} \mathrm{C}$ to different ages and equilibrated at $105{ }^{\circ} \mathrm{C}$ with "normal" atmospheric conditions (see text).

The peak at temperatures between $450{ }^{\circ} \mathrm{C}$ and $550{ }^{\circ} \mathrm{C}$ is due primarily to dehydration of portlandite, $\mathrm{Ca}(\mathrm{OH})_{2}$, but there also may be some contribution (on the order of $1 \%$ of the signal) of AFm dehydration in this range as well [15]. Mass loss above $550{ }^{\circ} \mathrm{C}$ is due primarily to decomposition of carbonates although, again, minor contributions due to the final dehydration of $\mathrm{C}-\mathrm{S}-\mathrm{H}$ gel and aluminate phases also are possible.

Figure 8 shows the influence of the prior heat treatment at $105^{\circ} \mathrm{C}$ on the TGA results for the same cement paste shown in Fig. 7. Both at $7 \mathrm{~d}$ and $14 \mathrm{~d}$ curing time, the small peak at $696{ }^{\circ} \mathrm{C}$, which appears when the normal atmosphere is used at $105{ }^{\circ} \mathrm{C}$, is suppressed when the dry atmosphere is used instead. Recall that the latter atmosphere, in addition to having much less moisture content $\left(-70{ }^{\circ} \mathrm{C}\right.$ dew point), also is virtually free of $\mathrm{CO}_{2}$. Any water loss at such high temperatures as even $500{ }^{\circ} \mathrm{C}$ must be due to water that is too tightly held to be lost at $105{ }^{\circ} \mathrm{C}$ even under dry conditions, as shown by the nearly identical size of the peak at $502{ }^{\circ} \mathrm{C}$ in Fig. 8. Therefore, the difference in the curves in that figure imply that the TGA peak at $696{ }^{\circ} \mathrm{C}$ is due to carbonation that occurs during the $105^{\circ} \mathrm{C}$ equilibration step. Although the peak is small in any case, it is a source of error when LOI is used to 
estimate the degree of hydration.

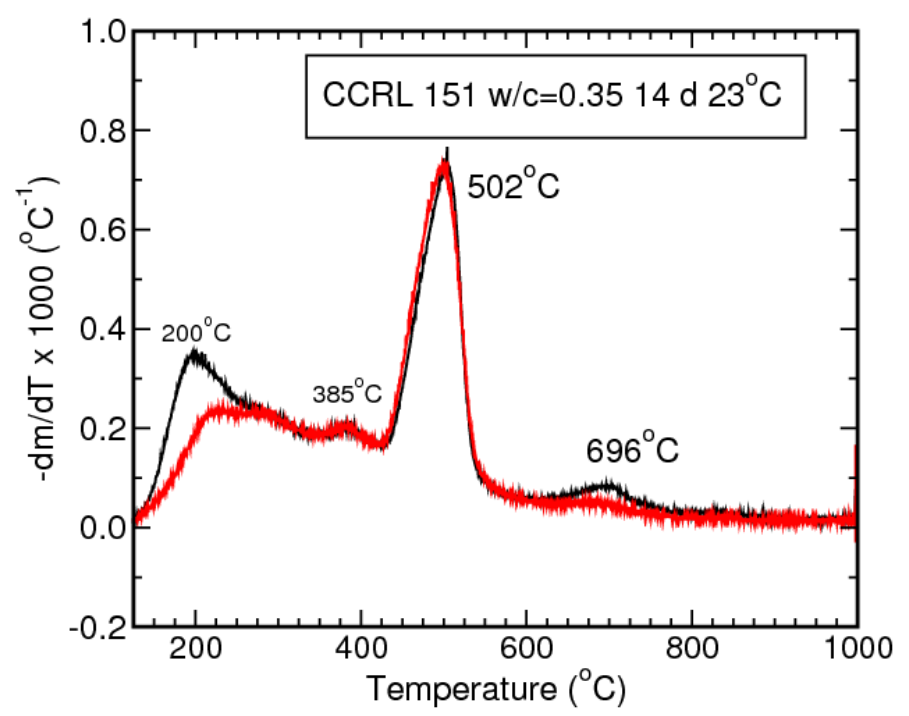

Figure 8: Differential mass loss as a function of temperature for cement 151 with $\mathrm{w} / \mathrm{c}=0.35$, cured at $23{ }^{\circ} \mathrm{C}$. The black curve was obtained after a $105{ }^{\circ} \mathrm{C}$ equilibration in ambient laboratory air, and the red curve was obtained after equilibration at the same temperature in dry and $\mathrm{CO}_{2}$-free air.

\subsection{Heat of Hydration}

The heat of hydration was determined by the testing laboratories using the ASTM C186 heat of solution test method [2]. For this test, cement pastes with w/c $=0.4$ were prepared and stored in sealed vials (sealed curing conditions) at $23{ }^{\circ} \mathrm{C}$. At the time of testing, either $7 \mathrm{~d}$ or $28 \mathrm{~d}$, the cement paste specimen was digested in an acid solution and the heat released was measured. By subtracting this measured value from the value determined for the starting cement powder, the heat of hydration was determined [2]. To predict these values using VCCTL, hydration of a w/c $=0.4$ cement paste under sealed conditions at $23{ }^{\circ} \mathrm{C}$ was conducted for cements 151 and 152. In Fig. 9, the simulated heats of hydration of both cements as a function of time is compared with the average values measured by the testing laboratories at $7 \mathrm{~d}$ and at $28 \mathrm{~d}$. The values of the time conversion factor used for the predicted curves shown in the figure are $\beta=0.00031 \mathrm{~h} /$ cycle $^{2}$ and $\beta=0.00033 \mathrm{~h} /$ cycle $^{2}$ for cements 151 and 152, respectively. For both cements, the value of $\beta$ was chosen to lie between the values that fit the LOI data at $w / c=0.35$ and $w / c=0.45$. In each case the predictions fit the measurements to within one standard deviation of the values obtained by the testing laboratories. For cement 152, the fit between prediction and experiment is excellent at both ages. 

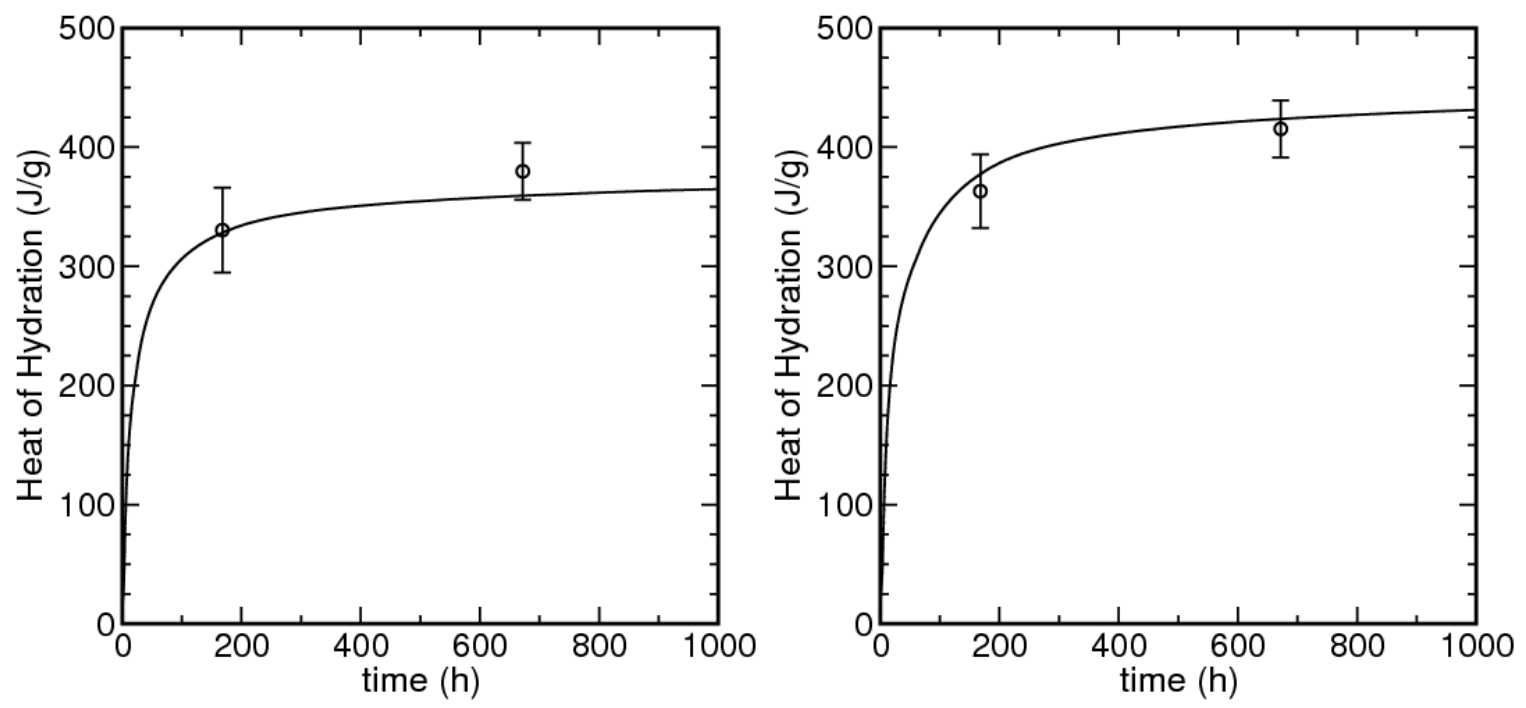

Figure 9: Computer model (lines) and experimental results (points) for the heat of hydration of cement 151 (left) and cement 152. Error bars represent plus/minus one standard deviation in the values measured by about 20 laboratories. For cement $151 \beta=0.00031$, and for cement $152 \beta=0.00033$.

\subsection{Setting Time}

At least two studies have shown that setting, as measured by the Vicat needle method, ASTM C 191 [2], correlates with the percolation of the solids in 3-D microstructural models of hydration $[4,16]$. The ASTM method [2] specifies that the initial and final setting times are to be measured on normal consistency (N.C.) pastes. For cements 151 and 152 , the N.C. water value measured by the testing laboratories was 25.4 and 26.0, respectively [3]. VCCTL was used to create 3-D microstructures of cements 151 and 152 with $\mathrm{w} / \mathrm{c}=0.254$ and $\mathrm{w} / \mathrm{c}=0.260$, respectively, and hydration of the microstructures was simulated under conditions like those specified in the Vicat needle method.

Figure 10 shows the fraction of solids connected as a function of time predicted by for cements 151 and 152. The open circles are predicted values and the error bars indicate the range of values predicted for two statistically identical microstructures. The solid curves are produced to guide the eye. Vertical dashed lines indicate the average experimental values of the initial and final time of set, as measured independently by 159 and 160 laboratories, respectively [3], using the Vicat needle technique described in the ASTM C191 standard test method [2].

The figure indicates that the percolated solid volume fraction gives an approximate indication of the time of set. In a previous study using CEMHYD3D [4], Bentz and coworkers found for CCRL proficiency samples 135 and 141 that solid fractions of 0.40 and 0.75 corresponded well with the intial and final setting times, respectively, measured by the Vicat method. For cement 151, Fig. 10 indicates that lower values, 0.10 and 0.65 , correlate with initial and final setting times, respectively. Using the previously published correlations for 

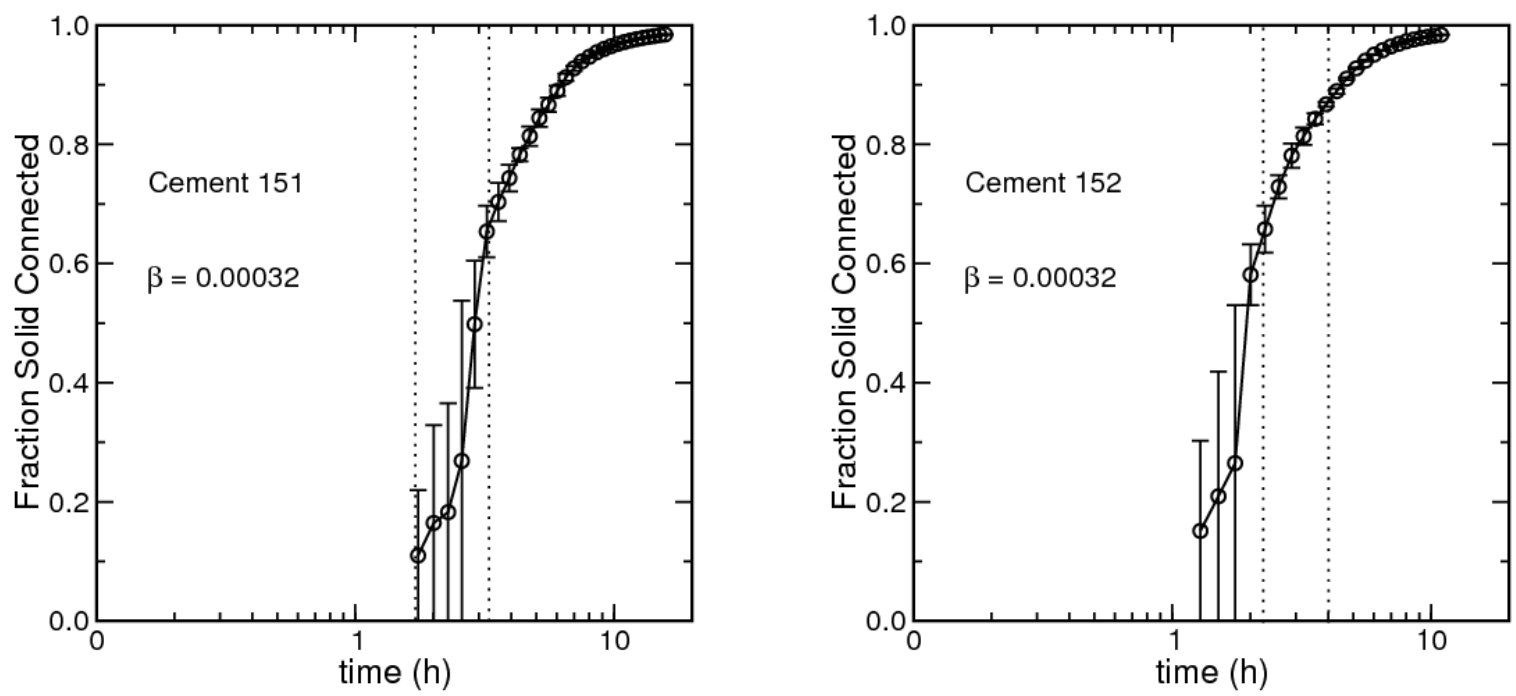

Figure 10: Volume fraction of connected solids as a function of time predicted by VCCTL for cements 151 (left) and 152. The vertical dashed lines indicate the experimentally measured initial and final setting times as measured by the Vicat needle method. Error bars in the predictions at any time indicate the range of values predicted on two statistically identical microstructures. The values of the time conversion factor are indicated on the plots.

samples 135 and 141 would result in a prediction of initial setting time that is about 20 min later than the value measured by the Vicat needle method [2].

For cement 152, the percolated solid volume fractions at initial and final set are 0.65 and 0.85 , respectively. In contrast to the behavior of cement 151, these values are somewhat higher than those reported for samples 135 and 141 [4]. In fact, using the values from that earlier study would result in a prediction of initial setting time that is about 20 min earlier than the measured value. But although the quantitative predictions for cements 151 and 152 differ somewhat from those made for samples 135 and 141, the general principal of the correlation appears to be valid.

\subsection{Mortar Strength Development}

Simulations of hydration of cements 151 and 152 were performed under conditions close to that specified in the ASTM C109 standard test method for mortar compressive strength [2]. Model cement paste microstructures with w/c $=0.485$ were created for both cements 151 and 152, and hydration was simulated with VCCTL at $23{ }^{\circ} \mathrm{C}$ under saturated conditions. The predicted and measured compressive strengths for cements 151 and 152 are shown in Fig. 11. Predictions are based on the the Powers gel-space ratio correlation between microstructure and compressive strength [15],

$$
\sigma=A X^{n}
$$


where $\sigma$ is the compressive strength, $X$ is the gel-space ratio, and $n$ is an exponent which is assumed to have a fixed value of 2.6, based on prior experience with VCCTL predictions for a number of cements $[5,7]$. The computer model calculates at each time the value of $X$ for the microstructure, and the prediction of compressive strength is made by calibrating the prefactor $A$ to an experimentally measured compressive strength at $3 \mathrm{~d}$ or $7 \mathrm{~d}$. The time conversion factors used for the predictions in Fig. 11 are the same as those used in Figs. 5 and 6 for $\mathrm{w} / \mathrm{c}=0.45$, namely 0.00027 and 0.00034 for cements 151 and 152, respectively.
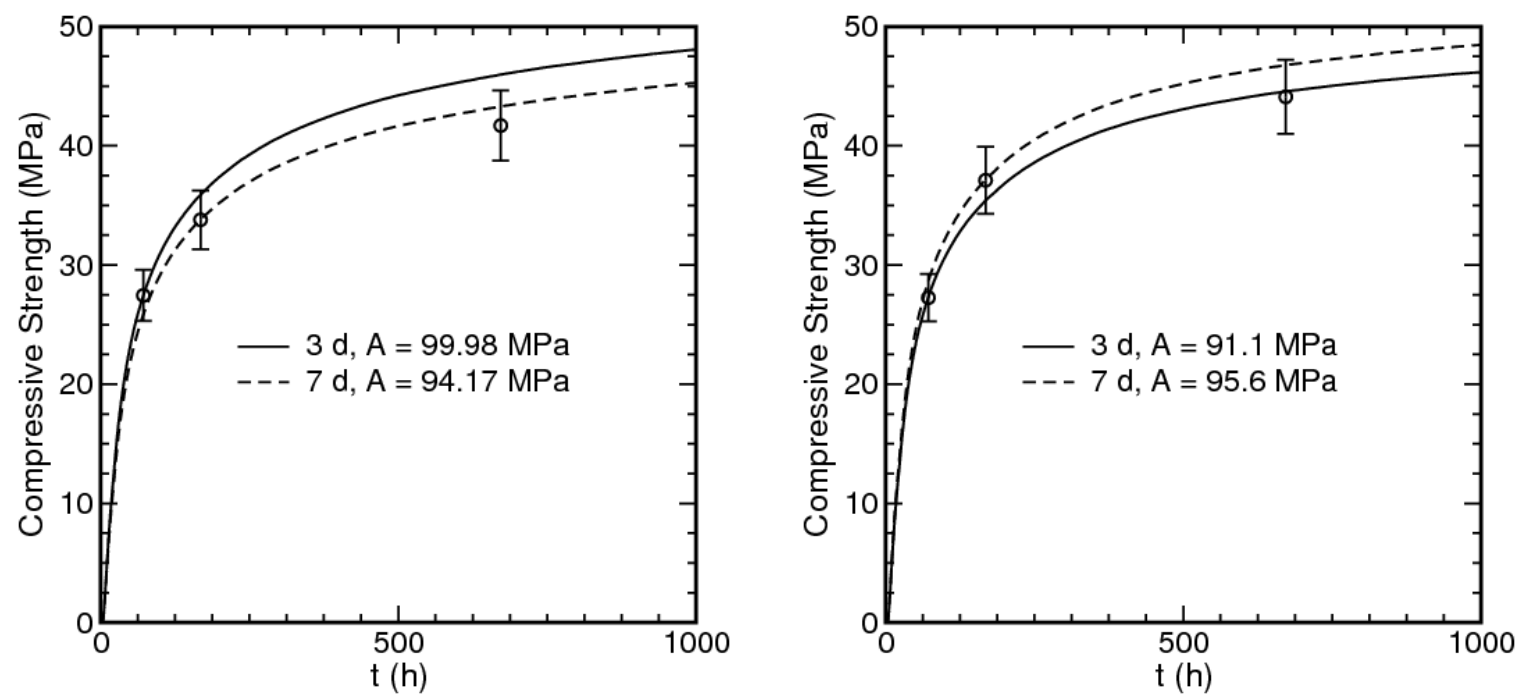

Figure 11: Computer model (lines) and experimental results (points) for the compressive strength of cement 151 (left) and cement 152. The solid and dashed curves were made by calibrating the prefactor to the $3-\mathrm{d}$ and $7 \mathrm{~d}$ strength measurement, respectively. Error bars represent plus/minus one standard deviation in the values measured by about 200 laboratories.

Fig. 11 indicates that better strength predictions are obtained for cement 151 by calibrating the prefactor $A$ to the $7 \mathrm{~d}$ experimental measurement instead of the $3 \mathrm{~d}$ measurement. In the past, it was observed for CCRL cements 135 and 136 that calibrating to the $7 \mathrm{~d}$ measured strength gave a superior fit to all of the experimental data [7]. Likewise for cement 151, using the $7 \mathrm{~d}$ measurement for calibration, all three values of the compressive strength fall within one standard deviation of the measured mean response. It is somewhat surprising that the predicted compressive strengths exceed the measured values in light of the fact that the predicted heats of hydration for cement 151, shown in Fig. 9, were actually less than the measured values.

As shown in Fig. 11, the situation is somewhat different for cement 152. Calibration of the coefficient $A$ to the $7 \mathrm{~d}$ experimental measurement results in predictions of compressive strength that are too high at $3 \mathrm{~d}$ and too low at $28 \mathrm{~d}$, although all three measurements still lie within one standard deviation of the predictions. However, calibrating $A$ to the strength measurement at $3 \mathrm{~d}$ results in a much better fit to the $28 \mathrm{~d}$ value. Again, the good fit to 
compressive strength measurements on cement 152 is compatible with the good fit to the heat of hydration data for that cement (see Fig. 9).

\section{Summary}

CCRL cements 151 and 152 have been quantitatively characterized based on SEM, Xray microanalysis, and QXRD. The phase compositions estimated from the SEM images are in close agreement with those measured by QXRD, but they are significantly different from those calculated using the formulas developed by Bogue, as in the appendix to the ASTM C150 specification. Based on the SEM/X-ray analysis, initial three-dimensional cement paste microstructures were created and hydrated using the VCCTL program. Model predictions for degree of hydration, heat of hydration, setting time, and mortar strength development were compared to their experimental counterparts. In most cases, good agreement between model predictions and experimental measurements was obtained when isothermal curing was simulated at $23{ }^{\circ} \mathrm{C}$. However, significantly poorer agreement was obtained for hydration kinetics at $60^{\circ} \mathrm{C}$, which indicates the need for more research on hightemperature microstructure development and on modifying VCCTL to more accurately simulate curing at higher temperatures. Furthermore, the prediction of $28 \mathrm{~d}$ compressive strength was too high compared to experimentally measured values, especially for cement 152.

Estimates of the degree of hydration using LOI measurements indicated a modest influence of the moisture content and $\mathrm{CO}_{2}$ levels during equilibration at $105^{\circ} \mathrm{C}$. Specifically, the estimated degree of hydration is significantly lower when a low-moisture, low- $\mathrm{CO}_{2}$ environment is used at $105^{\circ} \mathrm{C}$ than when ambient laboratory air is used. This effect is attributed to the harsher drying conditions which remove a greater mass of water at that temperature. TGA measurements indicated that a modest amount of carbonation of hydration products may occur during the treatment at $105^{\circ} \mathrm{C}$ when ambient air is used.

\section{Acknowledgments}

The authors acknowledge the Virtual Cement and Concrete Testing Laboratory Consortium for partial support of this research. Mr. Dale Bentz provided valuable information about the interpretation of the experimental data, and Mr. Max Peltz provided measurements of the particle size distribution of both cements.

\section{References}

[1] D. P. Bentz, P. E. Stutzman, C. J. Haecker, S. Remond, SEM/X-ray imaging of cement-based materials, in: H. S. Pietersen, J. A. Larbia, H. H. A. Janssen (Eds.), Proceedings of the 7th Euroseminar on Microscopy Applied to building Materials, Delft 
University of Technology, 1999, pp. 457-466, available online at the NIST electronic monograph, http://ciks.cbt.nist.gov/monograph, Part I, Chapter 4, Section 1.

[2] Annual Book of ASTM Standards, Vol. 04.01, ASTM International, West Conshohocken, PA, 2000.

[3] Final Report: Portland Cement Proficiency Samples Number 151 and Number 152, Cement and Concrete Reference Laboratory, 2004.

[4] C. J. Haecker, D. P. Bentz, X. P. Feng, P. E. Stutzman, Prediction of cement physical properties by virtual testing, Cement International 1 (3) (2003) 86-92.

[5] D. P. Bentz, Three-dimensional computer simulation of cement hydration and microstructure development, J. Am. Ceram. Soc. 80 (1) (1997) 3-21.

[6] D. P. Bentz, CEMHYD3D: A three-dimensional cement hydration and microstructural development modelling package. version 2.0, NISTIR 6485, U.S. Department of Commerce, available online at the NIST electronic monograph, http://ciks.cbt.nist.gov/monograph, Part I, Chapter 4, Section 2. (Apr. 2000).

[7] D. P. Bentz, X. Feng, C. J. Haecker, P. E. Stutzman, Analysis of CCRL proficiency cements 135 and 136 using CEMHYD3D, NISTIR 6545, U.S. Department of Commerce, available online at the NIST electronic monograph, http://ciks.cbt.nist.gov/monograph, Part I, Chapter 4, Section 3. (Aug. 2000).

[8] C. Ferraris, V. A. Hackley, A. I. Aviles, C. E. Buchanan, Analysis of the ASTM roundrobin test on particle size distribution of portland cement: Phase I, NISTIR 6883, U.S. Department of Commerce, available online at the NIST electronic monograph, http://ciks.cbt.nist.gov/monograph, Part I, Chapter 3, Section 8. (May 2002).

[9] C. Ferraris, V. A. Hackley, A. I. Aviles, C. E. Buchanan, Analysis of the ASTM roundrobin test on particle size distribution of portland cement: Phase II, NISTIR 6932, U.S. Department of Commerce, available online at the NIST electronic monograph, http://ciks.cbt.nist.gov/monograph, Part I, Chapter 3, Section 8. (Dec. 2002).

[10] D. P. Bentz, P. E. Stutzman, SEM analysis and computer modelling of hydration of portland cement particles, in: S. M. DeHayes, D. Stark (Eds.), Petrography of Cementitious Materials, American Society for Testing and Materials, Philadelphia, PA, 1994, pp. 60-73.

[11] P. E. Stutzman, J. R. Clifton, Specimen preparation for scanning electron microscopy, in: L. Jany, A. Nisperos (Eds.), Proceedings of the Twenty-First International Conference on Cement Microscopy, Las Vegas, NV, 1999, pp. 10-22, available online at the NIST electronic monograph, http://ciks.cbt.nist.gov/monograph, Part I, Chapter 3 , Section 3 . 
[12] K. R. Castleman, Digital Image Processing, Prentice-Hall, Englewood Cliffs, NJ, 1979.

[13] P. E. Stutzman, Powder diffraction analysis of hydraulic cements: ASTM rietveld round-robin results on precision, Powder Diffraction 20 (2) (2005) 97-100.

[14] S. Torquato, Random Heterogeneous Materials, Springer, New York, 2001.

[15] H. F. W. Taylor, Cement Chemistry, 2nd Edition, Thomas Telford, London, 1997.

[16] A. Princigallo, P. Lura, K. van Breugel, G. Levita, Early development of properties in a cement paste: A numerical and experimental study, Cem. Concr. Res. 33 (7) (2003) 1013-1020. 